\title{
MODELO DE AVALIAÇÃO DO DESEMPENHO DA GESTÃO DO SETOR PORTUÁRIO BRASILEIRO
}

\author{
Ismar Henriques Silveira ${ }^{1}$ \\ Katherine Helena Oliveira de Matos² \\ Maicon Lacerda ${ }^{3}$
}

RESUMO

O modelo de avaliação do desempenho da gestão do setor portuário denominado de GESPORTOS surgiu da necessidade de se conceber uma ferramenta, capaz de avaliar o nível de maturidade da gestão, a partir de características específicas do setor portuário, embasada em critérios reconhecidos e aceitos como o "estado da arte" da gestão. Este trabalho objetivou estruturar uma avaliação do desempenho da gestão direcionada ao setor portuário, considerando as suas especificidades, embasada em fundamentos reconhecidos e aceitos por organizações de classe mundial. Adotaram-se, como base do modelo, os mesmos fundamentos estabelecidos pela Fundação Nacional da Qualidade (FNQ) para o Prêmio Nacional da Qualidade (PNQ), entendendo-se estes, como referências universais e aplicáveis a qualquer tipo de organização, independente do seu negócio, porte e características específicas, permitindo assim a comparação com outras organizações de "classe mundial". Ao adotar os mesmos fundamentos do Modelo de Excelência, assumiu-se que estes são os pilares de sustentação das organizações que buscam a excelência na gestão como essência da sua competitividade, porém percebeuse a necessidade de uma adaptação dos critérios em função das particularidades do setor, que apresenta características únicas em relação a outros segmentos econômicos. Os resultados obtidos neste trabalho são úteis para a tomada de decisão, melhoria da gestão e aumento da competitividade deste importante segmento.

Palavras-chave: Modelo de Avaliação. Portos. Gestão. Desempenho. Gesportos.

\footnotetext{
${ }^{1}$ Especialista, e-mail: ismar@sc.senai.br

${ }^{2}$ Mestre, e-mail: katherine@sc.senai.br

${ }^{3}$ Especialista, e-mail: maicon@sc.senai.br
} 


\section{INTRODUÇÃO}

O Modelo de Excelência da Gestão (MEG), da Fundação Nacional da Qualidade (FNQ), traz, na sua essência, fundamentos que, como o nome sugere, são a base para excelência na gestão de toda e qualquer organização, são eles: Pensamento sistêmico, Aprendizado organizacional, Cultura da inovação, Liderança e constância de propósitos, Orientação por processos e informações, Visão de futuro, Geração de valor, Valorização das pessoas, Conhecimento sobre o cliente e o mercado, Desenvolvimento de parcerias e Responsabilidade social (FUNDAÇÃO NACIONAL DA QUALIDADE, 2009).

Para entender como estes fundamentos são (ou podem ser) aplicados as organizações, incluindo as portuárias, é essencial reconhecer que o papel da liderança é manter a constância de propósitos e estabelecer uma visão sistêmica de como a organização deve operar e interagir, interna e externamente. No entanto, isto não é suficiente. Ter constância de propósitos na direção errada pode ser tão ou mais prejudicial do que não ter constância de propósito. Dessa forma, é necessário que a organização tenha conhecimento sobre o cliente e o mercado, de tal forma que possa estabelecer uma visão de futuro, capaz de direcionar esforços e criar sinergia na direção certa.

Direcionar esforços e criar sinergia passa por buscar, reter e disseminar informação, promovendo assim o aprendizado organizacional que, por sua vez, deve levar a um repensar constante da organização, face ao dinamismo dos mercados. Portanto, consolidar uma cultura da inovação é essencial para assegurar a perpetuação do negócio. Ressaltase que, inovação deve ser entendida não somente como o desenvolvimento de novos produtos ou serviços, mas primordialmente, como uma nova postura organizacional.

A geração de resultados concretos depende da realização de um produto ou da prestação de um serviço. Neste contexto, a orientação por processos e informações é essencial. Por outro lado, sabe-se que processos não acontecem sem pessoas, por isso a valorização das pessoas é, muitas vezes, a condição necessária para o alcance dos resultados. E, quando os resultados estão acima da capacidade da organização, é necessário o desenvolvimento de parcerias. Gerar resultados consistentes e duradouros para a organização significa ter clareza sobre os mecanismos de geração de valor para as partes interessadas, não perdendo o foco de que a sustentabilidade de qualquer negócio depende, hoje, dos impactos gerados de seus processos, produtos e serviços na sociedade como um todo e, que atuar com responsabilidade social é uma premissa que deve ser demonstrada na prática.

Neste trabalho, entende-se como "porto", uma organização complexa, com atuação de diversos atores, cada um com papéis definidos e de forma independente. $\mathrm{O}$ modelo avaliativo proposto considera "porto" como o "complexo portuário", estabelecido conforme Figura 1, onde são apresentados alguns dos seus diversos órgãos intervenientes (atores). 
Figura 1: Complexo Portuário

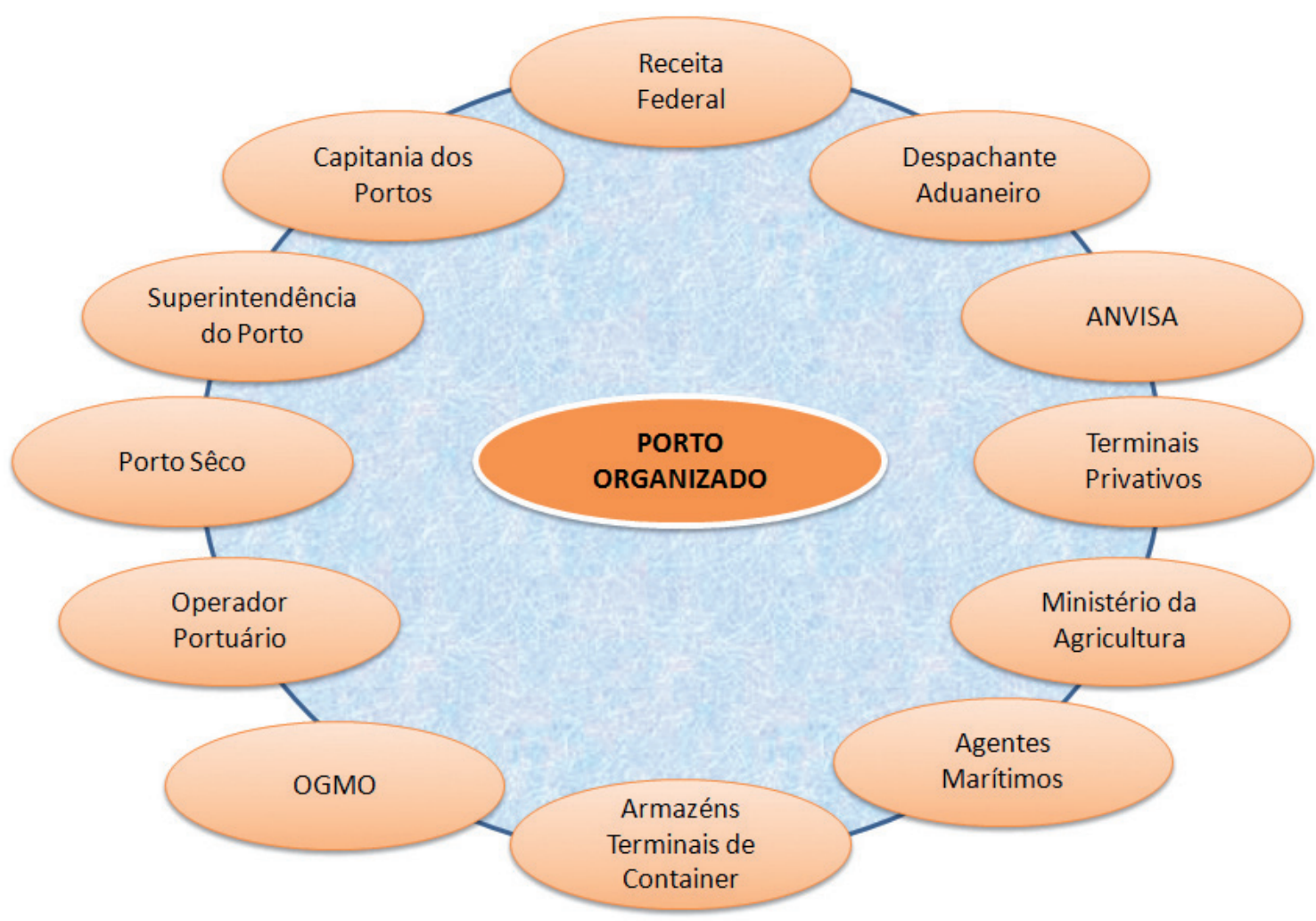

Fonte: Winkelmans (2008), adaptada pelos autores

Portos são instalações distintas em relação a seus ativos, funções e organizações institucionaise, ainda dentro de um mesmo porto, as atividades e serviços desempenhados são (ou podem ser) diferentes em seu escopo e natureza. Portos organizados são aqueles construídos e aparelhados para atender às necessidades da navegação e da movimentação e armazenagem de mercadorias, concedidos ou explorados pela União, cujo tráfego e operações portuárias estejam sob jurisdição de uma autoridade portuária (BIASO JR, 2006). Uma instalação portuária pode ser desde um pequeno cais para atracação de um navio até uma grande instalação com diversos terminais e estruturas de apoio industriais e de serviços.

A Lei 8.630 de 1993, criada para promover a modernização dos portos brasileiros, dispõe sobre o regime jurídico da exploração dos portos organizados e das instalações portuárias e dá outras providências, como retirar o Estado das operações portuárias, permanecendo este apenas na sua administração, enquanto as operações são realizadas por empresas privadas (BRASIL, 1993). As atividades e funções portuárias são identificadas por macroperspectivas políticas, geográficas, econômicas e sociais. Do ponto de vista das políticas públicas, os portos são como catalisadores econômicos das regiões em que atuam, onde a agregação de serviços e atividades cria benefícios econômicos e sociais. 
A operação portuária pode ser definida como o conjunto de todas as operações para realizar a passagem da mercadoria desde o transporte marítimo até o transporte terrestre e vice-versa. A operação portuária moderna se assemelha a uma atividade de produção de eventos, como um show, no qual uma grande quantidade de participantes (espectadores no show, cargas no porto) terá que ser satisfatoriamente atendidos pela equipe de produção, dentro de um prazo determinado e com certos padrões de qualidade e preço que tornem o evento viável, maximizando o uso das instalações existentes e tornando-as adequadas para o completo sucesso do evento.

De acordo com essa visão, os custos envolvidos, os prazos requeridos e as quantidades operadas, em conjunto, fazem com que a produtividade da operação seja condição fundamental para o atual sucesso de um porto, ou terminal. O trabalho portuário, que antes residia na força muscular do trabalhador, passou para uma escala na qual é praticamente impossível, e até mesmo perigoso, o uso de força humana na movimentação das cargas. Evoluiu para um estágio tecnológico, com uso de equipamentos cada vez mais possantes e velozes. Hoje o trabalho portuário é muito mais de inteligência, planejamento e preparo, que de força (FILHO, 2008). Os portos brasileiros enfrentam atualmente um grande aumento da demanda por seus serviços, em razão do aumento das importações e, principalmente, das exportações por via marítima (LACERDA, 2008).

A estrutura portuária é muito complexa e pode ser composta de infinitas instalações, assim para melhor entendimento das atividades e funções desempenhadas dentro de um porto organizado, são apresentadas algumas definições:

a) Porto: complexo composto por vários terminais, equipamentos portuários, fundeadouro (o fundeadouro serve para a embarcação pernoitar em segurança, facilita a espera de operações de carga e descarga), canal de acesso ao porto, vias de acesso ferroviário, rodoviário e fluvial, etc.;

b) Terminal portuário: é a unidade menor em que é dividido um porto e que é administrada independentemente por um operador portuário privado ou, quando a administração é estatal, pela União, Estado ou Município. Pode ser composto por um ou mais berços de atracação. São normalmente especializados em tipos de cargas ou de navios;

c) Cais e berço de atracação: cais é a estrutura, uma plataforma, onde os navios efetuam embarque e desembarque de carga ou passageiros. Berço é a posição de atracação de um terminal ou porto onde a embarcação entra para as suas operações;

d) Pátios ou armazéns: são os locais utilizados para acomodação das cargas a serem embarcadas, ou aquelas desembarcadas dos navios;

e) Equipamentos portuários: São os guindastes, empilhadeiras, transportadores, correias, tubulações, enfim, todos os equipamentos ou estruturas adequadas para movimentação, embarque e desembarque de carga geral, carga granel sólida carga granel líquida, containeres, etc. 
Dentro da estrutura administrativa, de um porto organizado, destacam-se as seguintes entidades:

a) Conselho de Autoridade Portuária (CAP): Responsável pela regulamentação sobre a exploração portuária, horário de funcionamento do porto, homologação dos valores das tarifas portuárias, estímulo à competitividade, tomada de medidas para desenvolver o porto, entre outros assuntos de interesse para a melhoria dos portos e suas operações;

b) Órgão Gestor de Mão-de-Obra (OGMO): Tem a função de administrar o fornecimento da mão-de-obra e controle do trabalho avulso portuário e trabalho portuário. O operador portuário - as responsabilidades destes operadores portuários são em relação à administração do porto, às mercadorias movimentadas, aos trabalhadores portuários, ao OGMO e ao seu contratante, que poderá ser o armador, exportador ou importador.

c) Agência Marítima: É a empresa que representa o armador em determinado país, estado, cidade ou porto, fazendo a ligação entre este e o usuário do navio. Não é comum o contato do usuário com o armador, diretamente, sendo esta função exercida pelo Agente Marítimo. Este agente poderá ser uma empresa do próprio armador, ou uma empresa independente, contratada pelo mesmo para representá-lo e para prestação de serviços (KEEDI e MENDONÇA, 2003).

d) Non-Vessel Operating Common Carrier (NVOCC) ou Transportador comum não-proprietário de navio: Trata-se de um armador sem navio, virtual, e que se propõe a realizar transporte marítimo em navios de armadores tradicionais constituídos. É uma forma de ter/manter o controle sobre uma parte do navio sem ter que, efetivamente, comprá-lo ou fretá-lo e nem administrá-lo ou operá-lo (KEEDI e MENDONÇA, 2003).

e) Despachante aduaneiro: É o responsável pela realização dos trâmites necessários ao desembaraço aduaneiro de mercadorias importadas ou a exportar, nas áreas alfandegadas. Ele opera por conta e ordem do importador ou exportador, na qualidade de representante legal e por mandato, de acordo com a legislação vigente. O Despachante Aduaneiro prepara e assina os documentos e papéis que servem de base ao procedimento fiscal, denominado despacho aduaneiro, na importação e na exportação (KEEDI e MENDONÇA, 2003).

Publicações da Secretaria de Portos demonstram que a costa brasileira possui cerca de 8,5 mil quilômetros navegáveis, movimentando anualmente cerca de 700 milhões de toneladas, respondendo por mais de $90 \%$ dos transportes das exportações do país. A Figura 2 apresenta o mapa de localização de todos os portos do território brasileiro. 
Figura 2: Localização dos portos na costa brasileira.

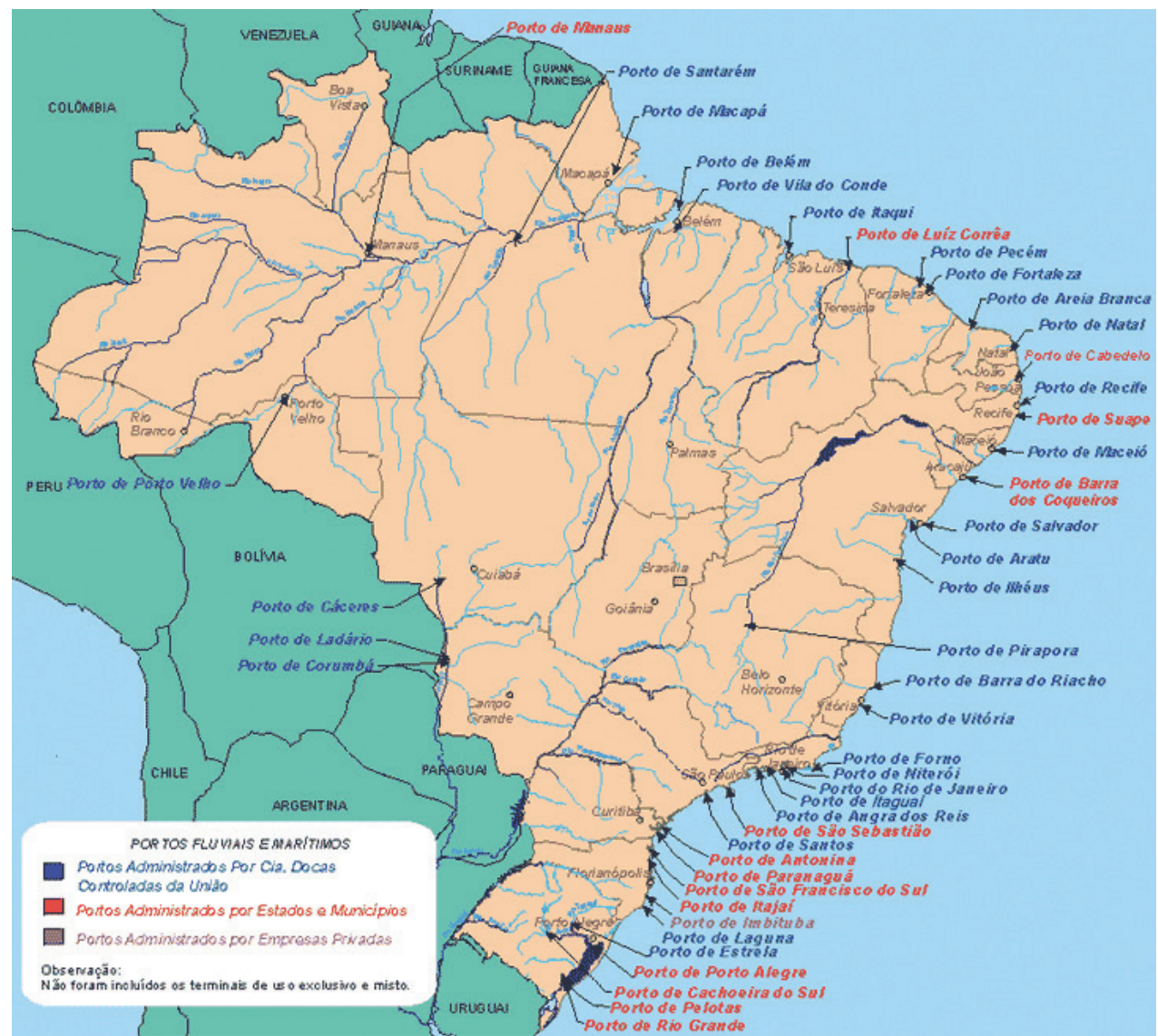

Fonte: Agência Nacional de Transportes Aquaviários (2010).

O sistema portuário brasileiro é composto por 37 (trinta e sete) portos públicos, sendo 18 (dezoito) delegados, concedidos ou tem sua operação autorizada à administração por parte dos governos estaduais e municipais. Além disso, ainda existem 42 (quarenta e dois) terminais de uso privativo e três complexos portuários que operam sob concessão à iniciativa privada. No próximo item será apresentada a metodologia utilizada para desenvolver o modelo de avaliação do desempenho da gestão do setor portuário brasileiro. 


\section{O MODELO DE AVALIAÇÃO DE DESEMPENHO DA GESTÃO PORTUÁRIA}

O modelo de avaliação de desempenho da gestão portuária considerou uma visão evolutiva, calcado na pirâmide de Maslow, que parte de questões diretamente relacionadas com a operação portuária até se chegar à percepção de como as necessidades e expectativas dos clientes e de outras partes interessadas são consideradas na formulação das estratégias e na definição do modelo de gestão, trazendo como foco a capacidade de captar a demanda do cliente e transformar esta demanda em processos que viabilizem soluções.

Para reforçar o "foco no cliente", o modelo preconizou a aplicação de uma pesquisa ou outra ferramenta estruturada capaz de ouvir a "voz do cliente", embasando assim a percepção da avaliação feita in loco e reafirmando a visão finalística de que os resultados devem ser orientados para o cliente. Assim, considerou-se que a percepção do cliente deve ser estabelecida com base em 04 (quatro) atributos finalísticos:

a) Previsibilidade: Considera o maior ou menor grau de envio (exportação) ou recebimento (importação) de mercadorias realizadas dentro do prazo (sem atrasos). Avaliação pode ser quantitativa com base no percentual de envios / recebimentos realizados no prazo previsto dentro de um determinado período. Os níveis considerados são definidos como alto (acima de $70 \%$ ), médio (entre 40 e $60 \%$ ) ou baixo (abaixo de $40 \%$ );

b) Produtividade: Do ponto de vista da operação portuária a produtividade é avaliada pela taxa de embarque (prancha), no entanto para o cliente esta avaliação pode demasiadamente subjetiva. Neste caso, a produtividade pode ser associada à questão anterior, pois ambas apresentam uma forte interação;

c) Perdas: Associado à integridade patrimonial (roubos, perdas ou danos na carga);

d) Preço: Percepção de valor do cliente.

Além dos fundamentos apresentados, o modelo considerou que toda organização é um ser vivo e dinâmico e que, por isso, possui necessidades que precisam ser atendidas dentro de uma hierarquia pré-estabelecida. Neste contexto, a Pirâmide de Maslow (Figura 3) foi considerada como base para a priorização dos processos organizacionais e estruturas necessárias ao desempenho da atividade portuária. 


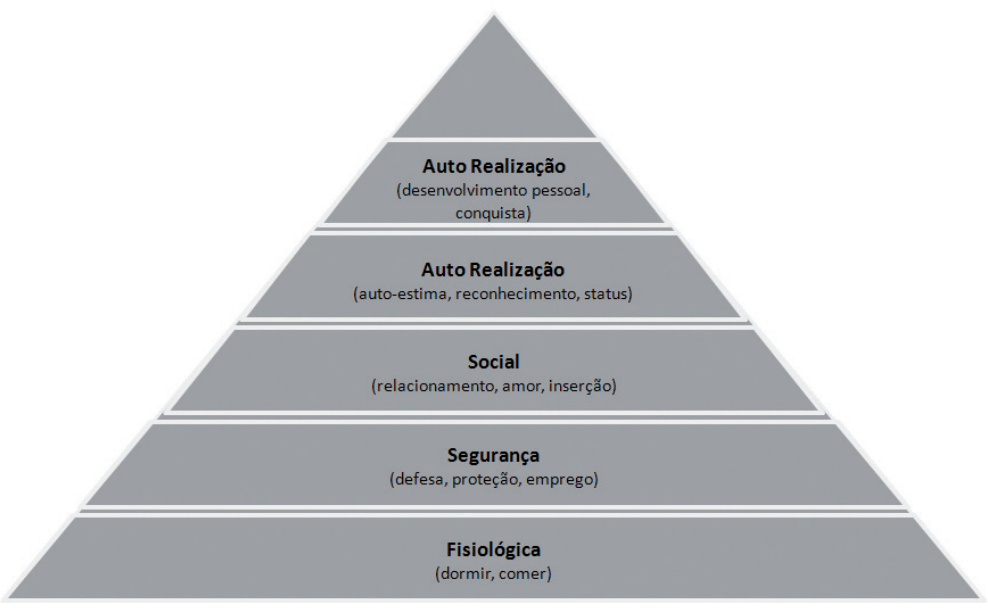

Fonte: Maslow (1954), adaptado pelos autores

As necessidades, descritas na Pirâmide de Maslow, foram adaptadas à realidade da atividade portuária:

a) Necessidades Fisiológicas: Características representativas da sobrevivência; aquelas associadas à entrada e saída da carga, entrada e saída do navio e operações de carga e descarga. Podem ser associadas ao acesso terrestre e aquaviário; infra-estrutura e mão de obra;

b) Necessidades de Segurança: Características representativas da estabilidade (confiabilidade); aquelas associadas à segurança da carga e do navio. Podem ser associadas às condições da operação, segurança patrimonial, sinalização, etc.;

c) Necessidades Sociais: Necessidades de exposição. Podem ser associadas à visibilidade (divulgação e promoção) do complexo portuário. Podem incluir, além da percepção do cliente, a percepção das demais partes interessadas;

d) Necessidades de Autoestima: Necessidades de reconhecimento. Podem ser consideradas práticas de benchmarking e a existência de ações para a melhoria;

e) Necessidades de Autorrealização: Necessidade de desenvolvimento através da utilização das capacidades e potencialidades. Demonstração através de práticas e resultados alcançados de uma evolução do desempenho. 
A partir das necessidades, foi possível associar a cada um dos níveis (necessidades) a um nível correspondente no modelo de avaliação, conforme o Quadro 1:

\section{Quadro 1: Associação dos níveis: necessidades x modelo avaliativo}

\begin{tabular}{|c|c|}
\hline \multicolumn{2}{|c|}{ Nível } \\
\hline Sobrevivência & 1 \\
\hline Estabilidade & II \\
\hline Exposição & III \\
\hline Reconhecimento & IV \\
\hline Desenvolvimento & $\mathrm{V}$ \\
\hline
\end{tabular}

Fonte: Dos autores

Além da aplicação da Pirâmide de Maslow na definição de níveis a serem galgados, o modelo considerou também aspectos relativos à atividade portuária, tais como: o tipo de carga movimentado, a maior ou menor proximidade de centros produtivos, a vocação econômica da região, etc. Estes aspectos foram tratados de forma diferenciada, através da atribuição de pesos diferentes para cada aspecto, por exemplo, um porto cuja movimentação de carga a granel corresponda a $80 \%$ da sua movimentação total, sendo feita através de ferrovia, não poderá ser penalizado fortemente por apresentar acesso rodoviário deficiente.

A Figura 4 apresenta o enfoque do modelo aplicado aos níveis estabelecidos com base na pirâmide de Maslow, onde foi possível associar:

a) Níveis I e II: com requisitos dos processos operacionais e de apoio;

b) Níveis III e IV: com requisitos dos processos de gestão;

c) Nível V: com os resultados gerados por estes processos, sendo avaliados na ótica do cliente. 
Figura 4: Associação dos níveis com requisitos.

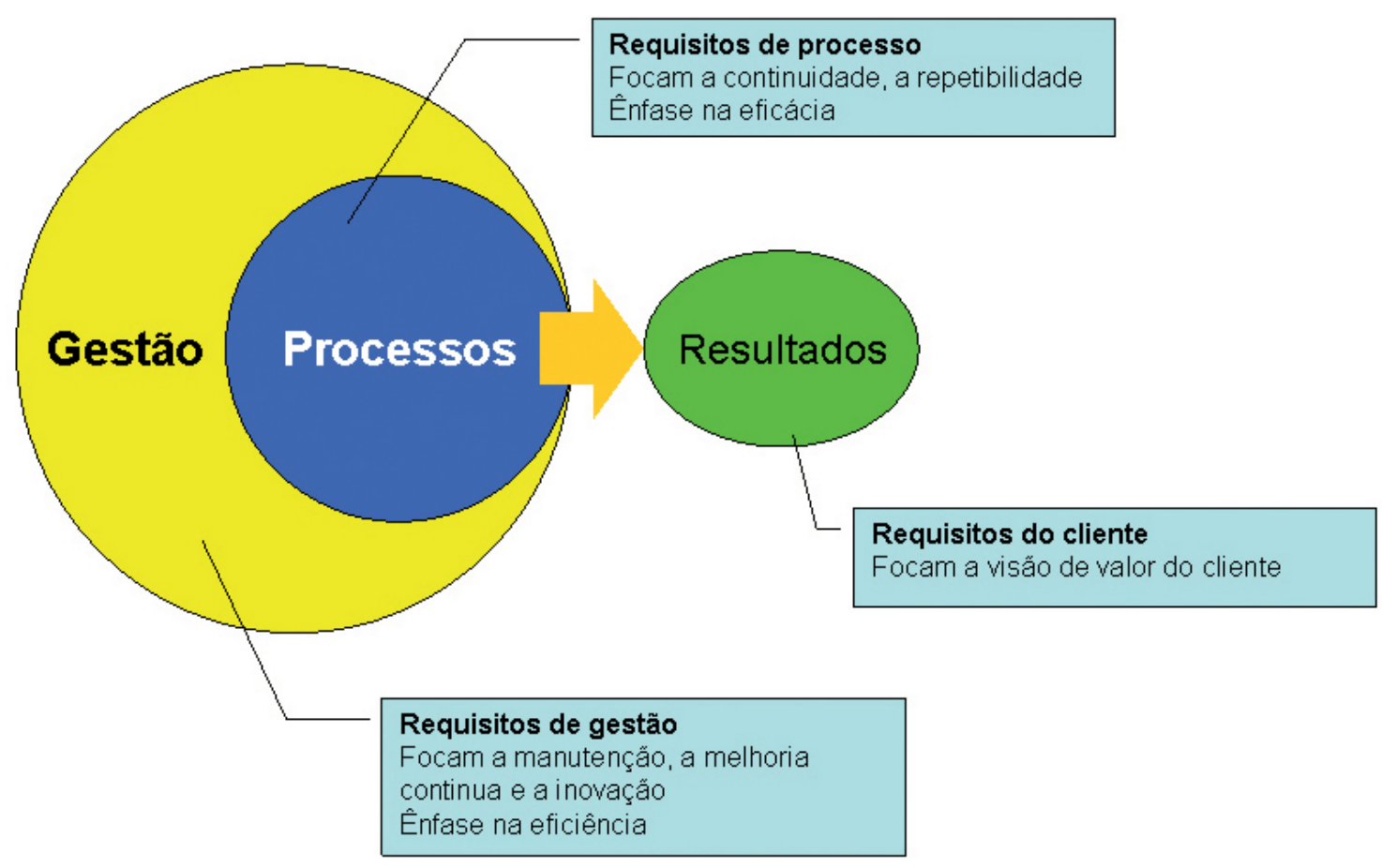

Fonte: Dos autores

\subsection{Sistema de pontuação e aspectos avaliativos}

Tomando-se por base o modelo da Fundação Nacional da Qualidade "Rumo a Excelência" que adota uma pontuação de 500 pontos, considerando-se que o modelo é evolutivo e deve demonstrar a evolução da gestão, além de ter o propósito de melhorar os resultados sempre na ótica do cliente e das partes interessadas, foi possível estabelecer as faixas de pontuação (Quadro 2) para cada nível valorizando os níveis que contribuem de forma mais expressiva para a geração de valor para o cliente e para as partes interessadas.

Quadro 2: Faixas de pontuação

\begin{tabular}{|l|l|l|l|}
\hline \multicolumn{2}{|l|}{ Nível } & \multicolumn{2}{l|}{ Faixas de pontuação } \\
\hline I & Sobrevivência & $10 \%$ & 0 a 50 \\
II & Estabilidade & $10 \%$ & 51 a 100 \\
III & Exposição & $20 \%$ & 101 a 200 \\
IV & Reconhecimento & $20 \%$ & 201 a 300 \\
V & Desenvolvimento & $40 \%$ & 301 a 500 \\
\hline
\end{tabular}

Fonte: Dos autores 
Para aplicação do modelo, foram identificados aspectos relacionados à atividade portuária (Quadro 3), que seriam avaliados em cada um dos níveis.

\section{Quadro 3: Aspectos avaliativos}

\begin{tabular}{|l|l|}
\hline Nível & Aspectos avaliativos \\
II & a) Acesso terrestre \\
& b) Acesso aquaviário \\
& c) Infra-estrutura - (incluindo sinalização) \\
d) Pessoas (incluindo SST) \\
a) Aquisição \\
b) Gestão financeira \\
c) Disponibilidade \\
dII Programação \\
e) Segurança da operação \\
f) Segurança patrimonial \\
g) Volume de movimentação (constância X sazonalidade) \\
a) Gestão estratégica \\
b) Mercado (foco no cliente) \\
c) Responsabilidade social \\
d) Marketing (divulgação e promoção) \\
e) Partes interessadas \\
f) Comunicação \\
a) Medição do desempenho \\
b) Benchmarking \\
c) Tomada de decisão \\
d) Ações de melhoria. \\
a) Evolução dos resultados
\end{tabular}

Fonte: Dos autores 


\subsection{Premissas do modelo}

Para a construção do modelo de avaliação do desempenho da gestão portuária, foram consideradas as seguintes premissas:

a) Aplicar os fundamentos estabelecidos pela Fundação Nacional da Qualidade para Prêmio Nacional da Qualidade, que são:

1) Pensamento sistêmico,

2) Aprendizado organizacional,

3) Cultura da inovação,

4) Liderança e constância de propósitos,

5) Orientação por processos e informações,

6) Visão de futuro,

7) Geração de valor,

8) Valorização das pessoas,

9) Conhecimento sobre o cliente e o mercado,

10) Desenvolvimento de parcerias,

11) Responsabilidade social;

b) Entender "porto" como complexo portuário;

c) Considerar aspectos relativos à atividade portuária tais como o tipo de carga movimentado, a maior ou menor proximidade de centros produtivos, a vocação econômica da região, etc. onde estes aspectos sejam tratados de forma diferenciada através da atribuição de pesos diferentes para cada aspecto;

d) Apresentar uma visão evolutiva da gestão (pirâmide de Maslow);

e) Possibilitar a avaliação da capacidade da gestão de captar a demanda do cliente e transformar esta demanda em processos que viabilizem soluções;

f) Demonstrar que os resultados alcançados são orientados para o cliente;

g) Considerar 04 (quatro) atributos finalísticos, que são: previsibilidade, produtividade, perdas e preço. 
Para realizar a avaliação do desempenho da gestão portuária verificando na prática a implementação dos fundamentos, foram estabelecidos quatro blocos que contemplam os fundamentos e que podem ser inter-relacionados com os níveis de maturidade estabelecidos anteriormente com base na pirâmide de Maslow (Quadro 4).

Quadro 4: Estabelecimentos dos blocos.

\begin{tabular}{|c|c|c|c|}
\hline \multicolumn{2}{|c|}{ Bloco } & Fundamentos envolvidos & Enfoque \\
\hline 1 & Estratégia & $\begin{array}{l}\text { Liderança e constância de } \\
\text { propósitos; } \\
\text { Conhecimento sobre o cliente e o } \\
\text { mercado; } \\
\text { Visão de futuro. }\end{array}$ & $\begin{array}{l}\text { Avalia como a Liderança utiliza o } \\
\text { conhecimento sobre o cliente e } \\
\text { o mercado, estabelece a visão de } \\
\text { futuro e assegura a constância de } \\
\text { propósitos }\end{array}$ \\
\hline 2 & Processos & $\begin{array}{l}\text { Desenvolvimento de parcerias; } \\
\text { Orientação por processos e } \\
\text { informações; } \\
\text { Valorização das pessoas. }\end{array}$ & $\begin{array}{l}\text { Avalia como a visão de futuro é } \\
\text { transformada em processos de } \\
\text { agregação valor para as partes } \\
\text { interessadas. Como as parcerias são } \\
\text { estabelecidas para assegurar esta } \\
\text { geração de valor e como as pessoas } \\
\text { são consideradas e valorizadas } \\
\text { neste processo. }\end{array}$ \\
\hline 3 & $\begin{array}{l}\text { Informação e } \\
\text { Conhecimentos }\end{array}$ & $\begin{array}{l}\text { Aprendizado organizacional; } \\
\text { Pensamento sistêmico; } \\
\text { Cultura da inovação. }\end{array}$ & $\begin{array}{l}\text { Avalia como o aprendizado } \\
\text { organizacional é estabelecido e } \\
\text { sistematizado gerando uma cultura } \\
\text { da inovação. }\end{array}$ \\
\hline 4 & Resultados & $\begin{array}{l}\text { Geração de valor (para as partes } \\
\text { interessadas); } \\
\text { Responsabilidade social. }\end{array}$ & $\begin{array}{l}\text { Avalia a efetividade (eficiência + } \\
\text { eficácia) da geração de valor para } \\
\text { as partes interessadas e o impacto } \\
\text { social destas atividades. }\end{array}$ \\
\hline
\end{tabular}




\subsection{Matriz Avaliativa}

A partir dos blocos estabelecidos, foi realizada a interação entre os Blocos e Níveis (matriz avaliativa), sendo que a avaliação do fundamento realizada onde está identificado com " $X$ " (Figura 5). E ainda, cada "aspecto avaliativo", identificado na Matriz avaliativa (Figura 5), deve ser analisado do ponto de vista dos atributos finalísticos.

Figura 5: Matriz avaliativa.

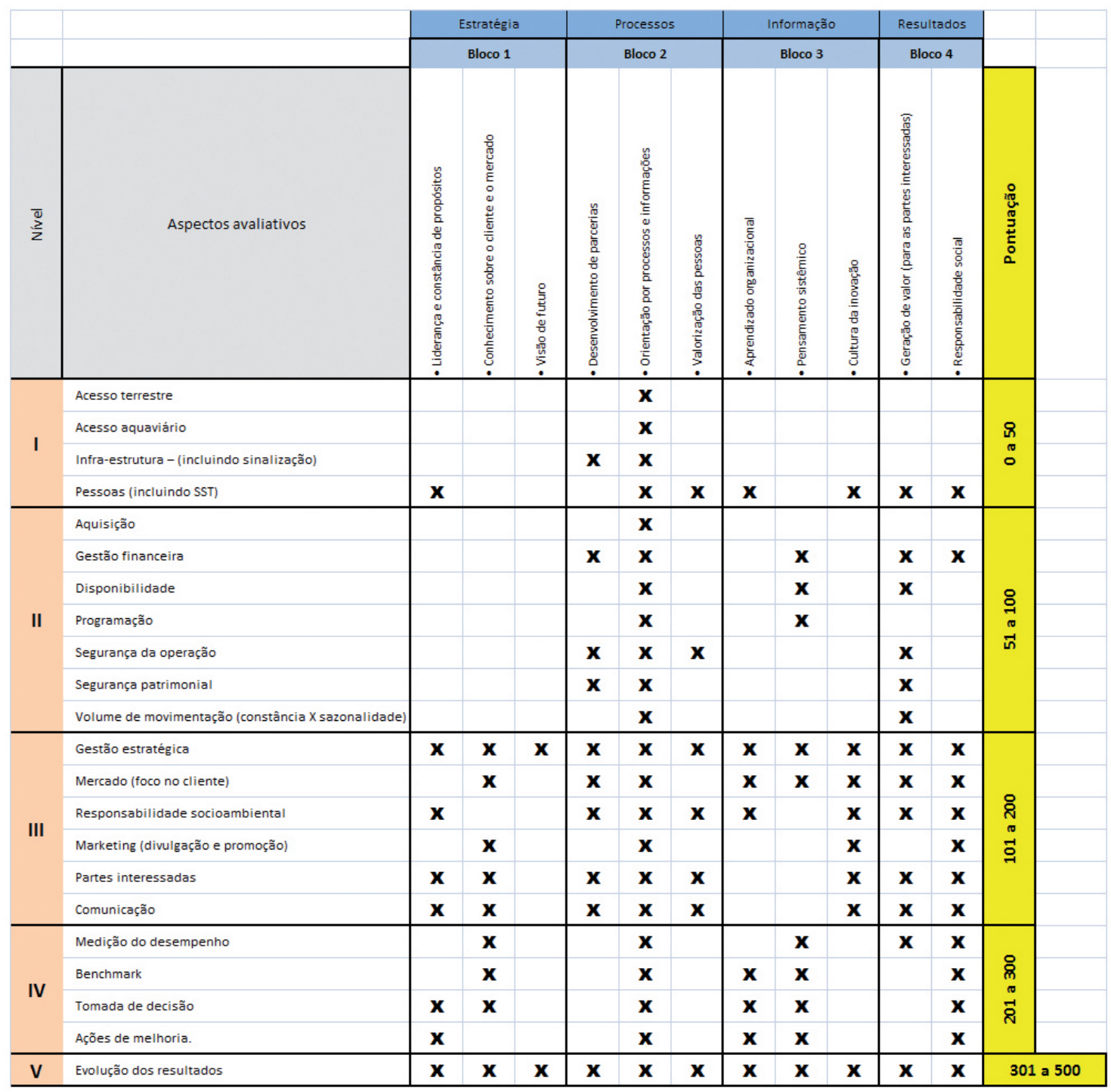


Para exemplificar, o Quadro 5 indica a análise do impacto do aspecto "Acesso terrestre" em cada atributo.

Quadro 5: Análise do impacto do aspecto avaliativo "Acesso terrestre" em cada atributo.

\begin{tabular}{|l|l|l|l|l|}
\hline \multirow{2}{*}{ Aspecto avaliativo } & \multicolumn{4}{|l|}{ Atributo Finalístico } \\
\cline { 2 - 5 } & Previsibilidade & Produtividade & Perdas & Preço \\
\hline Acesso terrestre & Alta & Média & Média & Alto \\
\hline
\end{tabular}

Fonte: Dos autores

É importante destacar que, para cada aspecto avaliativo, será necessária uma interpretação do atributo finalístico em relação ao aspecto. Por exemplo: para o aspecto "Acesso terrestre", o atributo "previsibilidade" pode ser entendido como garantia de acesso, o atributo "produtividade" como facilidade de acesso ou tempo de acesso, o atributo "perdas" com custos gerados para o transportador e o atributo "preço" com os investimentos necessários para melhoria e manutenção do acesso.

\subsection{Processo de Avaliação do Desempenho da Gestão Portuária}

O modelo de avaliação do desempenho da gestão portuária pode ser aplicada aos diversos atores do complexo portuário (Figura 1) levando em consideração as suas atribuições e interações, sendo que, para cada bloco, devem ser estabelecidos interlocutores que responderam por eles.

A avaliação será realizada através da aplicação de check-list e da realização de entrevistas com os principais executivos, lideranças e outros formadores de opinião, iniciando sempre pelo Nível I e prosseguindo para os demais níveis, desde que atendidos os níveis mínimos de pontuação definidos em 3.4. Caso o nível mínimo de pontuação não seja atingido, o processo de avaliação deve ser encerrado no nível em que se encontra.

\subsection{Sistemática de Pontuação}

A sistemática de pontuação considera inicialmente as interseções estabelecidas na Matriz Avaliativa (item 3.2), onde para cada interseção é definido um valor com base na maior ou menor interação, entre fundamento e aspecto avaliativo, de forma a totalizar o número de pontos estabelecido para o nível. A Figura 6 apresenta um exemplo referente ao nível I. 
Figura 6: Exemplo de pontuação para os aspectos avaliativos do Nível I.

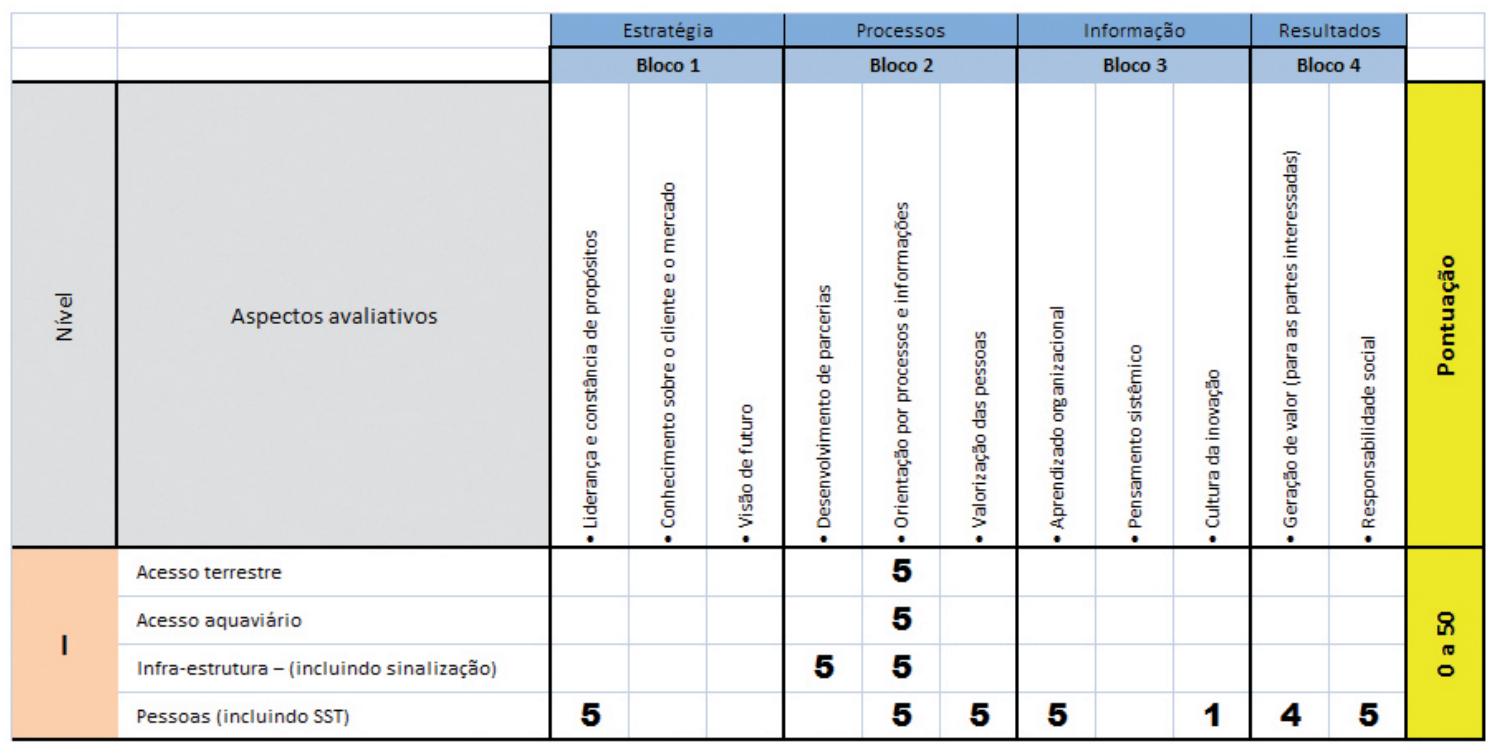

Fonte: Dos autores

Após análise do "aspecto avaliativo", devem-se avaliar os "fatores finalísticos" relacionados ao aspecto. O Quadro 6 apresenta a tendência desejada para cada atributo e o percentual atribuído para cada tendência desejada.

Quadro 6: Tendência desejada para cada atributo e o \% atribuído para cada tendência desejada.

\begin{tabular}{|l|l|l|l|l|}
\hline \multirow{2}{*}{ Tendência } & \multicolumn{4}{|l|}{ Atributo Finalístico (\%) } \\
\cline { 2 - 5 } & Previsibilidade & Produtividade & Perdas & Preço \\
\hline Alta & 25 & 25 & 0 & 0 \\
Média & 12,5 & 12,5 & 12,5 & 12,5 \\
Baixa & 0 & 0 & 25 & 25 \\
\hline
\end{tabular}

Fonte: Dos autores

Para fins de exemplo, considerando que, após avaliação da tendência de cada aspecto em relação aos atributos, os resultados encontrados foram àqueles indicados no Quadro 7. 
Quadro 7: Resultados da avaliação da tendência de cada aspecto.

\begin{tabular}{|l|l|l|l|l|}
\hline \multirow{2}{*}{ Aspecto avaliativo } & \multicolumn{3}{|l|}{ Atributo Finalístico - Tendência } \\
\cline { 2 - 5 } & Previsibilidade & Produtividade & Perdas & Preço \\
\hline Acesso terrestre & Alta & Média & Média & Alto \\
Acesso aquaviário & Média & Média & Alta & Alto \\
Infra-estrutura - (incluindo sinalização) & Alta & Alta & Baixa & Baixa \\
Pessoas (incluindo SST) & Média & Média & Média & Alto \\
\hline
\end{tabular}

Fonte: Dos autores

Como conseqüência, os percentuais obtidos para cada atributo são aqueles indicados no Quadro 8.

Quadro 8: Percentuais obtidos para cada atributo.

\begin{tabular}{|l|l|l|l|l|}
\hline \multirow{2}{*}{ Aspecto avaliativo } & \multicolumn{3}{|l|}{ Atributo Finalístico (\%) } \\
\cline { 2 - 5 } & Previsibilidade & Produtividade & Perdas & Preço \\
\hline Acesso terrestre & 25 & 12,5 & 12,5 & 0 \\
Acesso aquaviário & 12,5 & 12,5 & 0 & 0 \\
Infra-estrutura - (incluindo sinalização) & 25 & 25 & 25 & 25 \\
Pessoas (incluindo SST) & 12,5 & 12,5 & 12,5 & 0 \\
\hline
\end{tabular}

Fonte: Dos autores

Finalmente, é possível obter o resultado final da pontuação (Quadro 9).

Quadro 9: Resultado final da pontuação.

\begin{tabular}{|l|l|l|l|c|}
\hline Aspecto avaliativo & Pontuação (Max) & $\%$ & Pontos & $\begin{array}{l}\text { Pontuação } \\
\text { Final }\end{array}$ \\
\hline Acesso terrestre & 5 & 50 & 2,5 & \\
Acesso aquaviário & 5 & 25 & 1,25 & 25 \\
Infra-estrutura - (incluindo sinalização) & 10 & 100 & 10 & \\
Pessoas (incluindo SST) & 30 & 37,5 & 11,25 & \\
\hline
\end{tabular}

Fonte: Dos autores 


\subsection{Ouvindo a voz do cliente}

Além da matriz avaliativa, foi destacado, no item 2, a importância da aplicação de uma pesquisa ou outra ferramenta estruturada, que seja capaz de ouvir a "voz do cliente". Dessa forma, há um balizamento entre a percepção da avaliação feita in loco, e reafirmando a visão finalística de que os resultados devem ser orientados para o cliente. Desta forma, considerou-se que os resultados obtidos pela avaliação in loco podem ser analisados, com uma visão do cliente em relação à real importância do se está avaliando. Afinal, não há nada pior do que fazer bem algo que não precisava ser feito. Neste sentido, é necessário priorizar bons resultados naqueles aspectos avaliativos que realmente façam a diferença para o cliente. Assim, para identificação dos critérios/atributos mais importantes nos serviços prestados pelo setor portuário podem ser utilizados os seguintes métodos:

a) Pesquisa qualitativa descritiva: descrevendo situações de mercado a partir de dados primários, podendo ser quantitativos ou qualitativos. As pesquisas descritivas compreendem uma série de técnicas de levantamento de dados como questionário, entrevista estruturada, pesquisa por telefone, entre outros (DENCKER, 2000).

b) Modelo Delphi: utilizado para confirmar as informações através de duas rodadas. Esse procedimento consiste em uma pesquisa, mediante um questionário aplicado a um conjunto de formadores de opinião, para obter considerações e muitas vezes integrar perspectivas do futuro. Os formadores de opinião não trabalham juntos, porém cada um deles apresenta a sua opinião por escrito, de forma livre, sem que nenhum dos outros participantes conheça suas opiniões. O método Delphi consiste no envio de um questionário a um grupo de formadores de opinião. O número de etapas do questionário é variável, dependendo do assunto que será tratado (TRIOLA, 1999).

\section{CONCLUSÃO}

Neste trabalho, foramestabelecidas as diretrizes para o desenvolvimento e implementação de um modelo de avaliação do desempenho da gestão portuária. Para o desenvolvimento do modelo, foram considerados aspectos desde a utilização de fundamentos da gestão adotados por organizações de classe mundial, independentemente do tipo e porte, até a pontuação de aspectos específicos da atividade portuária.

A estrutura apresentada tem como principal função tornar o processo de avaliação objetivo, que possa ser disseminado, independentemente de quem o realize, e consiga estabelecer resultados que possam ser a base para a tomada de decisão. Outro ponto relevante é a possibilidade de comparação dos desempenhos alcançados, de forma que os melhores resultados possam ser conhecidos e associados às práticas que levaram aos resultados. Estas práticas seriam, então, disseminadas, gerando o aprendizado. 
Finalmente, ressalta-se que, a sistematização de um modelo não elimina ou sequer reduz a importância de quem irá aplicá-lo. O conhecimento dos princípios da gestão e das especificidades do setor é requisito essencial para que o modelo proposto possa ser executado de forma a gerar confiança na aplicação bem como nos resultados apurados.

\title{
MODEL FOR ASSESSING THE MANAGEMENT PERFORMANCE OF THE BRAZILIAN PORTS
}

\begin{abstract}
The model for assessing the management performance of the ports industry (GESPORTOS) arose from the need to develop a tool capable of evaluating the management maturity levels from specific features of the ports industry, based on criteria recognized and accepted as "state of the art"' management. This study aimed to design a performance evaluation of management, directed at the ports industry, considering its specific features and based on the fundamentals recognized and accepted by world-class organizations. Adopted as a model, were the same principles established by the National Quality Foundation (FNQ) for the National Quality Award (NQA), understanding these references as universal and applicable to any organization, regardless of their business, size and characteristics, thus allowing comparisons with other "world class" organizations. By adopting the same basis as the Excellence Model, it was assumed that these were the foundations supporting the organizations which seek excellence in management at the heart of their competitiveness, but it was noted that there was a need to adapt the criteria in specific aspects of the industry, which have unique characteristics compared to other economic industries. The results of this study are useful for decision making, improving management and increasing competitiveness in this important segment.
\end{abstract}

Key words: Assessment model. Ports. Management. Performance. 


\section{REFERÊNCIAS}

AGÊNCIA NACIONAL DE TRANSPORTES AQUAVIÁRIOS. Brasília, 2010. Disponível em: < http://www.antaq.gov.br/Portal/default.asp?>. Acesso em: 03 maio 2011.

BIASO JR, A. O porto de Salvador: análise da realidade atual, suas necessidades e comparações pós lei 8.630/93. Rio de Janeiro: Pontifícia Universidade Católica do Rio de Janeiro, 2006. Disponível em: <http://www2.dbd.puc-rio.br/pergamum/ tesesabertas/0412254_06_cap_02.pdf>. Acesso em: 14 maio 2011.

BRASIL. Presidência da República, Casa Civil, Subchefia para Assuntos Jurídicos. LEI n.o 8.630 - Lei dos Portos. Brasília, 1993. Disponível em: <http://www.planalto.gov.br/ ccivil_03/leis/l8630.htm>. Acesso em: 07 maio 2008.

DENCKER, A. F. M. Métodos e Técnicas de Pesquisa em Turismo. 4. ed. São Paulo: Futura, 2000, $286 \mathrm{p}$.

FUNDAÇÃO NACIONAL DA QUALIDADE. Critérios de excelência 2010: avaliação e diagnóstico da gestão organizacional. São Paulo: FNQ, 2009. 109 p.

FILHO, J. E. F. A atividade portuária como ferramenta de Comércio exterior: o novo perfil e os desafios do trabalho nos portos. 2008. Disponível em: <http://cursos.aduaneiras. com.br/treinamento/estudecomex_2004/site_estudecomex/carreira_porto.htm>. Acesso em: 01 ago. 2008.

KEEDI, S.; MENDONÇA. P. C.C. Transportes e seguros no comércio exterior. 2. ed. São Paulo: Aduaneiras, 2003. $251 \mathrm{p}$.

LACERDA, S. M. O Transporte marítimo de longo curso no brasil e no mundo. Revista do BNDES, Rio de Janeiro, v. 11, n. 21, p. 209-232. Disponível em: < http://www.bndes.gov. br/conhecimento/revista/rev2107.pdf>. Acesso em: 05 ago. 2008.

MASLOW, Abraham H.. Motivation and personality. New York: Harper \& Brothers, 1954.

TRIOLA, M. Introdução à estatística, 7. ed. Rio de Janeiro:LTC, 1999.

WINKELMANS, W. One day conference on current trends and practices in the organization, operation and management of ports and terminals. Institute of Transport Maritime Management Antwerp. University of Antwerp. Greece, 2008. Disponível em: <http://hermes.civil.auth.gr/pgtransport/docs/Winkelmans_PORT_GOVERNANCE_ and_SRM_2008.pdf>. Acesso em: 01 out. 2012. 


\section{SOBRE OS AUTORES}

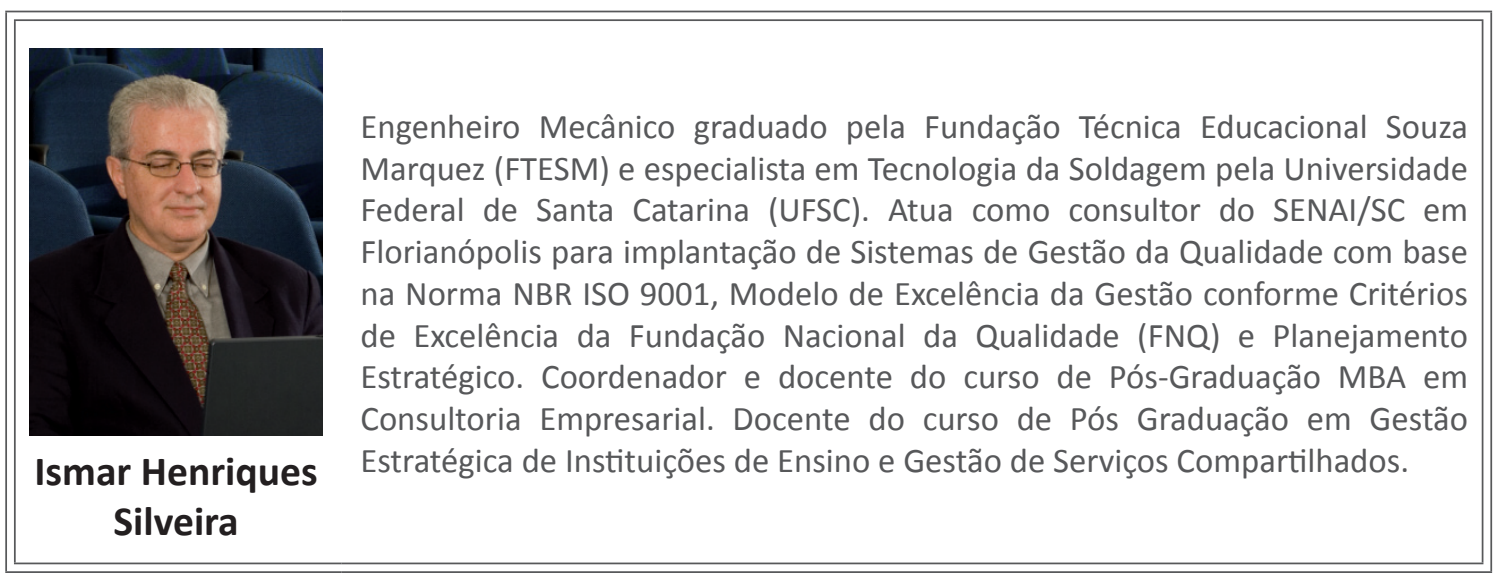

\begin{tabular}{|c|c|}
\hline $\begin{array}{c}\text { Katherine } \\
\text { Helena Oliveira } \\
\text { de Matos }\end{array}$ & $\begin{array}{l}\text { Engenheira de Alimentos graduada pela Universidade Federal de Santa Catarina } \\
\text { (UFSC) e mestre em Engenharia de Alimentos pela Universidade Federal de } \\
\text { Santa Catarina (UFSC). Doutoranda em Engenharia de Alimentos pela mesma } \\
\text { universidade. É Lead Assessor na ISO 22000:2005, consultora, auditora e } \\
\text { multiplicadora do Programa Alimentos Seguros (PAS) - Setor Indústria. Atuou } \\
\text { como instrutora e consultora do SENAI SC em Florianópolis para implantação } \\
\text { de Sistemas de Gestão para a Segurança de Alimentos. Foi docente do curso } \\
\text { de Pós-Graduação MBA em Gestão para Segurança de Alimentos à distância e } \\
\text { trabalhou na implementação e em auditorias internas de Sistemas de Gestão } \\
\text { de Qualidade e de Segurança de Alimentos em diversas indústrias da área pelo } \\
\text { SENAI. Atualmente é Coordena o Negócio de Consultoria em Gestão do SENAI } \\
\text { SC e a implantação do Instituto SENAI de Tecnologia - Alimentos. }\end{array}$ \\
\hline
\end{tabular}

\begin{tabular}{|l|l|}
\hline & $\begin{array}{l}\text { Administrador de Empresas e Pedagogo graduado pela Universidade do Sul de } \\
\text { Santa Catarina (UNISUL) e pós-graduado em Gestão Empresarial pela Fundação } \\
\text { Getúlio Vargas (FGV). Mestrando em Administração pela Universidade do Vale } \\
\text { do Itajaí (UNIVALI). É Lead Assessor na NBR ISO 9001:2008, atuou por mais } \\
\text { de cinco anos como consultor de empresas para implantação de sistemas de } \\
\text { gestão, examinador da Fundação Nacional da Qualidade (FNQ) nos ciclos de } \\
\text { 2008, 2009, 2010, } 2011 \text { e 2012, instrutor, conteudista de cursos a distância } \\
\text { eauditor nas áreas de gestão da qualidade, processos e fornecedores. } \\
\text { Coordenouo Núcleo de Gestão Empresarial do SENAI/SC em Florianópolis no } \\
\text { período de } 2009 \text { a 2011. Atualmente é Coordenador de Projetos do Núcleo de } \\
\text { Tecnologia e Inovação na Direção Regional do SENAI/SC. }\end{array}$ \\
\hline Maicon Lacerda
\end{tabular}

